\title{
A QUESTÃO DO CLIMA NO ESTABELECIMENTO DAS ESTÂNCIAS PAULISTAS
}

\author{
Silvio Luiz Cardoso Pinto ${ }^{1}$
}

\section{Lauro Luiz Francisco Filho²}

Resumo: Este artigo analisa a influência do clima no estabelecimento de estâncias climáticas no Estado de São Paulo. Para tanto planifica a conceituação do vocábulo clima e sua atuação dentro do Estado, bem como as (as) similaridades climáticas entre as estâncias já estabelecidas, através da comparação estatística de dados climáticos obtidos junto à instituições oficiais.

Palavras Chave: Clima. Estância. Estância climática.

\section{INTRODUÇÃO}

Ao estabelecer as primeiras "estâncias" no Estado de São Paulo, em 1926, a administração pública paulista buscava mitigar os efeitos nocivos, impostos pelas epidemias que se impunham. A tuberculose, a febre amarela, o tifo entre outras, provocaram pesadas baixas às populações urbanas, adensadas ao longo do eixo produção/exportação, delimitado pela cultura do café. (ALESP: 2012)

\footnotetext{
${ }^{1}$ Mestrando da Faculdade de Engenharia Civil, Arquitetura e Urbanismo da Universidade Estadual de Campinas (UNICAMP)

${ }^{2}$ Professor da Faculdade de Engenharia Civil, Arquitetura e Urbanismo da Universidade de Estadual Campinas - UNICAMP e Pesquisador do LABINUR (Laboratório de Investigações Urbana)/UNICAMP
} 
A recente libertação dos escravos, a chegada da imigração européia e o exôdo rural, entre outros fatores, aceleraram o crescimento desordenado de cidades estratégicas, ofertando condições ideias para a proliferação das epidemias.

A abertura da Pensão São Matheus para tísicos, em 1874 no atual município de Campos do Jordão, estabelece as bases para a criação das primeiras estâncias Sanitárias, em outubro de 1926.

[...] onde se localizavam os sanatórios para doentes dos pulmões e, em 1920, da Vila Emílio Ribas. O fato de ter se tornado um local para tratamento de saúde concorreu para a criação da prefeitura sanitária em $1^{\circ}$ de outubro de 1926 [...] (SEADE: 2012)

Desde então os critérios para a criação de estâncias no Estado vem "evoluindo", e atualmente, segundo o Departamento de Apoio ao Desenvolvimento das Estâncias - DADE (2012), são quatro as possibilidades de enquadramento: Hidrominerais, turísticas, balneárias e Climáticas. Os critérios para implantação de estâncias climáticas, dada sua subjetividade, oferecem campo para discussão e questionamentos em relação às propriedades terapeuticas de seus ares.

\section{OBJETIVOS}

O objetivo principal deste artigo é verificar até que ponto a influência do clima ratifica as condições para a elevação de um determinado município paulista à condição de estância climática. São objetivos secundários contextualizar o clima no estado e entender como a atuação deste pode promover (ou não) a implantação de estâncias climáticas, segundo critérios tecnicamente mais precisos.

\section{METODOLOGIA}

Um levantamento bibliográfico fundamenta este artigo, subsidiando a conceituação de clima e a forma como atua no Estado de São Paulo. Sistemas de classificação climática serão empregados para catalogar o clima no Estado, e a coleta de dados climáticos junto ao CEPAGRI da UNICAMP viabilizará a 
comparação paramétrica entre as estâncias. Os dados climáticos das dez estâncias climáticas paulistas, relativos a Latitude, longitude, altitude, temperaturas máximas, médias e mínima e o volume de chuvas, serão analisados de forma a ratificar (ou não) a condição de equidade existente entre elas.

\section{COLETA E INTERPRETAÇÃO DE DADOS}

\section{CLIMA}

O vocábulo clima vem do grego klíma, alusão ao ângulo imaginário formado pelo eixo de rotação da terra com seu plano de translação. Para Aurélio (2012), representa o conjunto de condições meteorológicas (temperatura, pressão e ventos, umidade e chuvas) características do estado médio da atmosfera em um ponto da superfície terrestre. Região onde a temperatura e demais condições atmosféricas são, em geral, as mesmas.

Para a Organização Meteorológica Mundial - OMM (1959) clima é "um conjunto flutuante de condições atmosféricas caracterizadas pelos estados e evolução do tempo no curso de um período suficientemente longo, em um domínio espacial determinado" (MARTINELLI, 2008, p. 02)

De forma genérica o Intergovernmental Panel on Climate Change (IPCC) entende Clima como o "tempo médio", ou de forma criteriosa, como a descrição estatística em função das médias e variabilidade, de quantidades relevantes ao longo de um período de tempo que varia de alguns meses a milhares ou milhões de anos. O período clássico para obter a média dessas variáveis definido pela OMM é de 30 anos. Em geral as informações relevantes referem-se a variações ocorridas na superfície, como temperatura, chuva e vento. Num sentido mais amplo clima é o estado, incluindo uma descrição estatística, do sistema climático. (IPCC, 2012)

Para o Instituto Nacional de Metereologia (INMET) clima é "um recurso natural vital ao nosso bem-estar, saúde e prosperidade. As informações coletadas, gerenciadas e analisadas ajudam tomadores de decisão e usuários a planejar e adaptar suas atividades e projetos às condições esperadas. As decisões podem ser tomadas no planejamento, reduzindo riscos e aperfeiçoando benefícios sócio- 
econômicos" (INMET, 2012).

Clima para Ministério da Agricultura, Pecuária e Abastecimento é o estado da atmosfera expresso por meio de temperaturas, chuvas, isolação, nebulosidade, etc., estudado com base nos registros de séries climáticas das condições atmosféricas que caracterizam uma região, por períodos superiores a 30 anos. Depende fortemente da posição em latitude do local considerado e do aspecto do substrato, é a diferença entre dois períodos consecutivos (30 anos), tida como uma flutuação climática (BRASIL, 2012).

Em suma, tempo é o que está acontecendo na atmosfera em momento qualquer, uma condição em um determinado instante, enquanto clima deve ter sua compreensão entendida em um determinado espaço de tempo. Cientificamente pode ser definido como a descrição estatística (em termos de média) e variabilidade de quantidades relevantes durante determinado período de tempo.

O clima deriva dos efeitos promovidos pela interação entre os elementos que determinam a dinâmica da terra: atmosfera (volume de gás que a envolve), a hidrosfera (parte do sistema que contém água em sua forma líquida), a criosfera (água em estado sólido), a litosfera de superfície, (camada superior de terra sólida nos continentes e nos oceanos suportando atividade vulcânica) e a biosfera ( que contém todos os organismos vivos e ecossistemas na terra e nos oceanos), e pode ser classificado de maneiras diferentes dependendo de quem precisa da informação, o volume e tipo de informação disponibilizada e necessária (INMET, 2012).

Situado dentro das Latitudes $5^{\circ}$ ao norte e $32^{\circ}$ ao sul, o Brasil apresenta grande variedade climática em seu território, com extensas regiões (Brasil central, região norte e sul) onde o clima é bem definido, enquanto a região sudeste apresenta várias tipologias climáticas. Segundo Rolim (2007, p. 712) "no Estado de São Paulo, devido ao seu relevo acidentado, posição geográfica e diferentes influências de massas de ar, constata-se grande diversidade climática, sendo complexo seu estudo". 


\section{Mapa 01 - Mapa de Clima do Brasil}

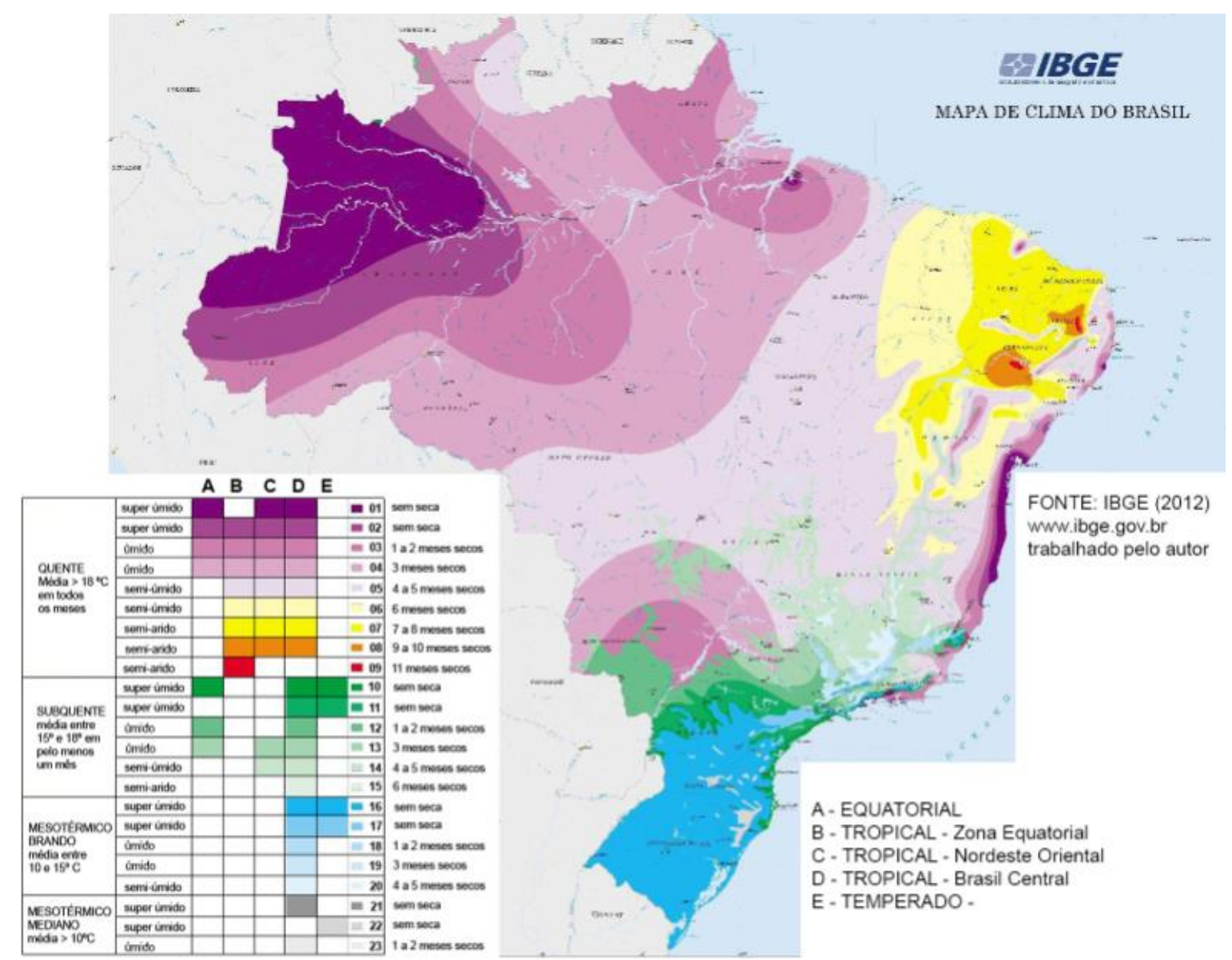

Para Pinto e Alfonsi (1972) apud Rolim (2007, p. 713), o próprio tipo e desenvolvimento da agricultura paulista são reflexos desta complexidade, acarretando diferenças significativas em potenciais de produtividades agrícolas. Setzer (1966) realizou o último mapeamento de tipos de clima para o Estado de São Paulo usando o SCC de Köppen e Geiger (1.928) cujo sistema assume que a vegetação natural é a melhor expressão do clima de uma região.

Os sistemas de classificações climáticas (SCC) são de grande importância, pois, analisam e definem os climas das diferentes regiões levando em consideração vários elementos climáticos ao mesmo tempo, facilitando a troca de informações e análises posteriores para diferentes objetivos. (ROLIM et al, 2007, p. 712)

KÖPPEN, GEIGER, THORNTHWAITE, SETZER desenvolveram Sistemas de Classificação Climática, ainda que o primeiro mapa de precipitação tenha sido 
produzido por OLSEN em 1839. (MARTINELLI, 2010, p. 03)

Mapa 02: Classificação Climática para o Brasil segundo Köppen-Geiger

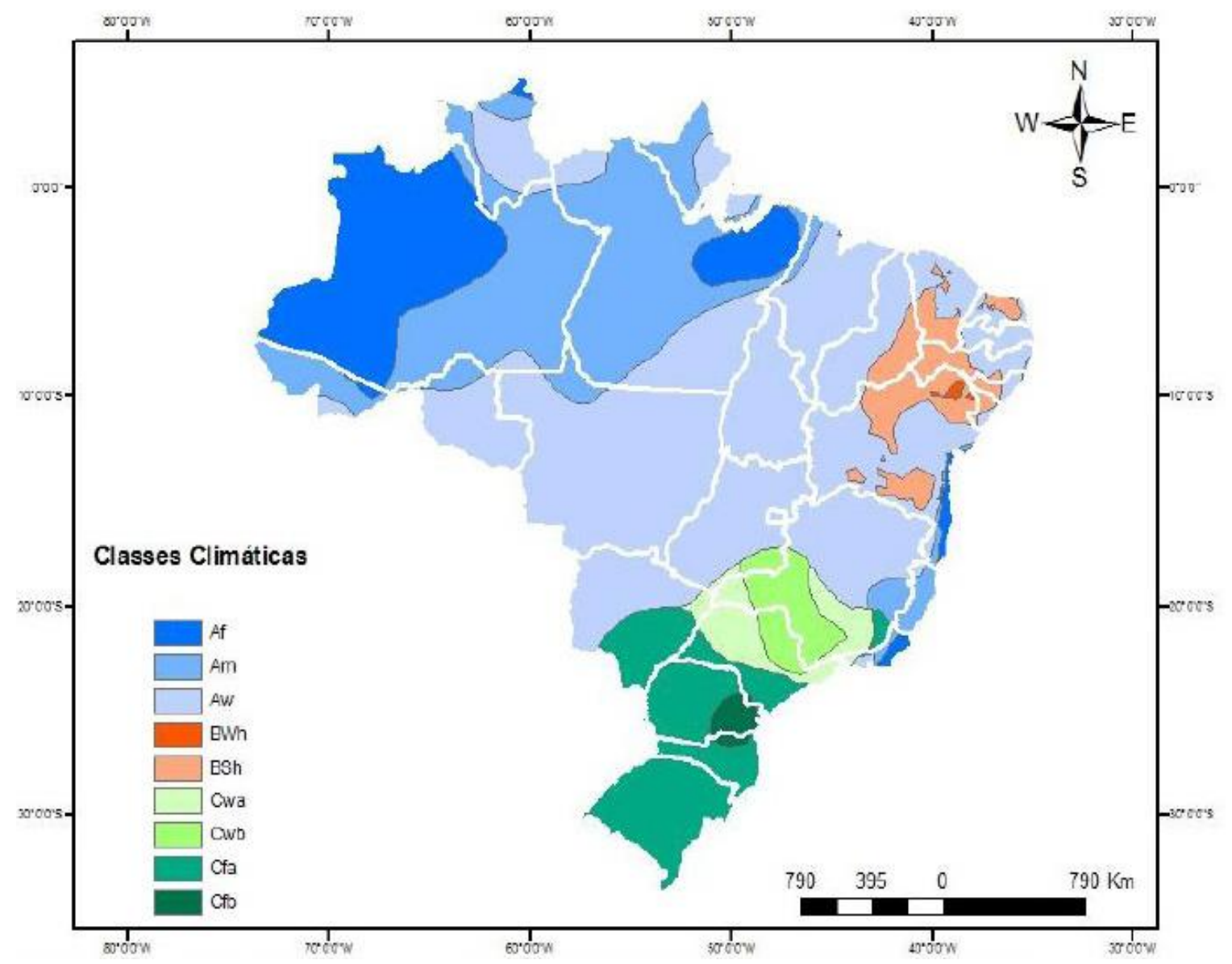

Fonte: (SAMPAIO, et al: 2011)

KÖPPEN, GEIGER, THORNTHWAITE, SETZER são exemplos de estudiosos que desenvolveram Sistemas de Classificação Climática, entretanto o primeiro mapa de precipitação foi realizado por OLSEN em 1839. (MARTINELLI, 2010, p. 03) 
Mapa 03: Classificação Climática para o Brasil segundo Thornthwaite

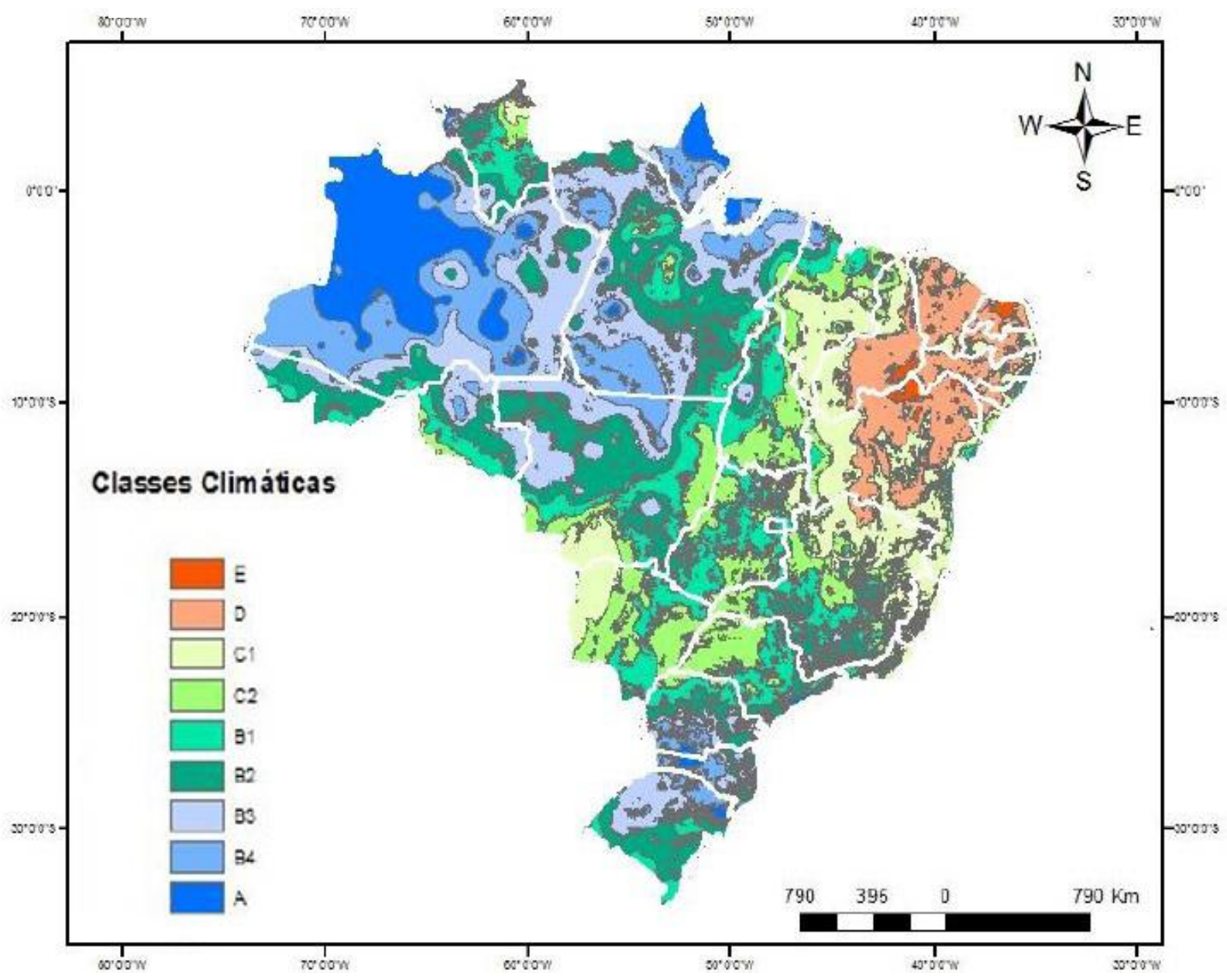

Fonte: (SAMPAIO et al: 2011)

O Estado de São Paulo dispõem de 27 estações termométricas e 427 postos pluviométricos, e segundo a Biblioteca Virtual do Governo de São Paulo, variando de acordo com o relevo, quatro tipos climáticos estão presentes no Estado: tropical super-úmido, tropical de altitude, tropical quente e úmido e subtropical úmido.

$\mathrm{Na}$ classificação proposta por Köppen, baseada em dados mensais (pluviométricos e termométricos), sete tipos climáticos distintos, estão presentes no Estado, a maioria correspondente a clima úmido, conforme se verifica no Quadro 01. 


\begin{tabular}{|c|c|c|c|c|c|}
\hline \multicolumn{6}{|c|}{ Quadro 01: Significado dos símbolos para a Classificação de Köppen } \\
\hline \multicolumn{2}{|r|}{ Clima característico } & \multicolumn{2}{|c|}{ Regime de chuvas } & \multicolumn{2}{|c|}{ Temperatura característica } \\
\hline \multirow{2}{*}{ A } & \multirow{2}{*}{ Quente e úmido } & f & Sempre úmido & \multirow{2}{*}{ h } & \multirow{2}{*}{ Quente } \\
\hline & & m & Moncônico e úmido & & \\
\hline \multirow{2}{*}{$\mathbf{B}$} & \multirow{2}{*}{ Árido ou semi-árido } & $\mathbf{s}$ & Chuvas de inverno & \multirow{2}{*}{ a } & \multirow{2}{*}{ Verổes quentes } \\
\hline & & $\mathbf{s}^{\prime}$ & Chuvas de outuno & & \\
\hline \multirow{2}{*}{ C } & \multirow{2}{*}{$\begin{array}{l}\text { Mesotérmico (sub- } \\
\text { tropical ou tropical }\end{array}$} & $w$ & Chuvas de verẫo & \multirow{2}{*}{ b } & \multirow{2}{*}{ Verỗes brandos } \\
\hline & & $w^{\prime}$ & Chuvas de verẫo/outono & & \\
\hline
\end{tabular}

A classificação climática de Köppen para São Paulo (Mapa 04), mostra as regiões mais quentes a Noroeste com clima $A w$ - tropical chuvoso, inverno seco e temperatura média no mês mais frio superior a $18^{\circ} \mathrm{C}$ e precipitação inferior a $60 \mathrm{~mm}$, com atraso do período chuvoso para o outono.

Mapa 04: Classificação Climática para São Paulo proposta por Köppen

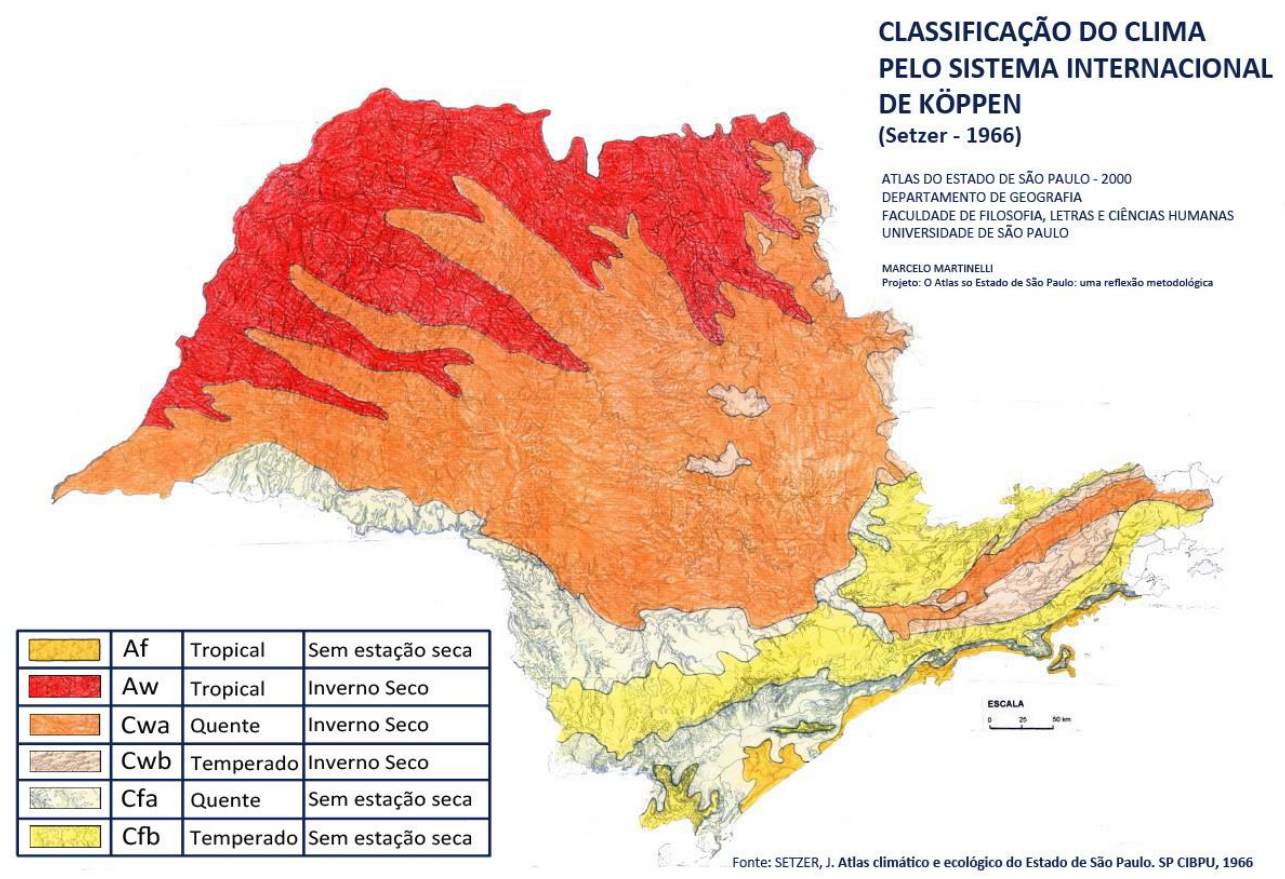

Fonte: Setzer; 1966 
Dominante o Cwa abrange toda a parte central, caracteriza-se como tropical de altitude, com verão úmido e inverno seco, temperatura média no mês mais quente superior a $22^{\circ} \mathrm{C}$. Áreas serranas, com verão ameno são classificadas como Cwb, com temperatura média do mês mais quente é inferior a $22^{\circ} \mathrm{C}$.

Faixas de clima tropical são observadas no sul do Estado. Com verão quente e sem estação seca no inverno, o Cfa apresenta temperatura média do mês mais frio entre $18^{\circ} \mathrm{C}$ e $-3^{\circ} \mathrm{C}$ (mesotérmico). Nas serras do Mar e Mantiqueira, as regiões mais altas apresentam verão ameno e chuvoso, clima classificado como Cfb e precipitação média no mês mais seco superior a $60 \mathrm{~mm}$.

O trabalho apresentado por Martinelli (2007), que analisa graficamente através do Mapa 05 os índices de pluviosidade para o Estado. Com isoietas selecionadas para os valores 1120,1200, 1300, 1400, 1500,1700, 2000, 3000, 4000 $\mathrm{mm}$ e ordem visual crescente entre as cores frias aplicadas entre as isolinhas, revela nítida presença de mais valores elevados na fachada atlântica da Serra do Mar junto à Baixada Santista e Litoral Norte e na vertente oriental da Serra da Mantiqueira, com um decrescendo de valores conforme se vai do litoral para o interior. (Martinelli, 2008, p. 06)

Mapa 05: Pluviosidade Total Anual para o Estado de São Paulo

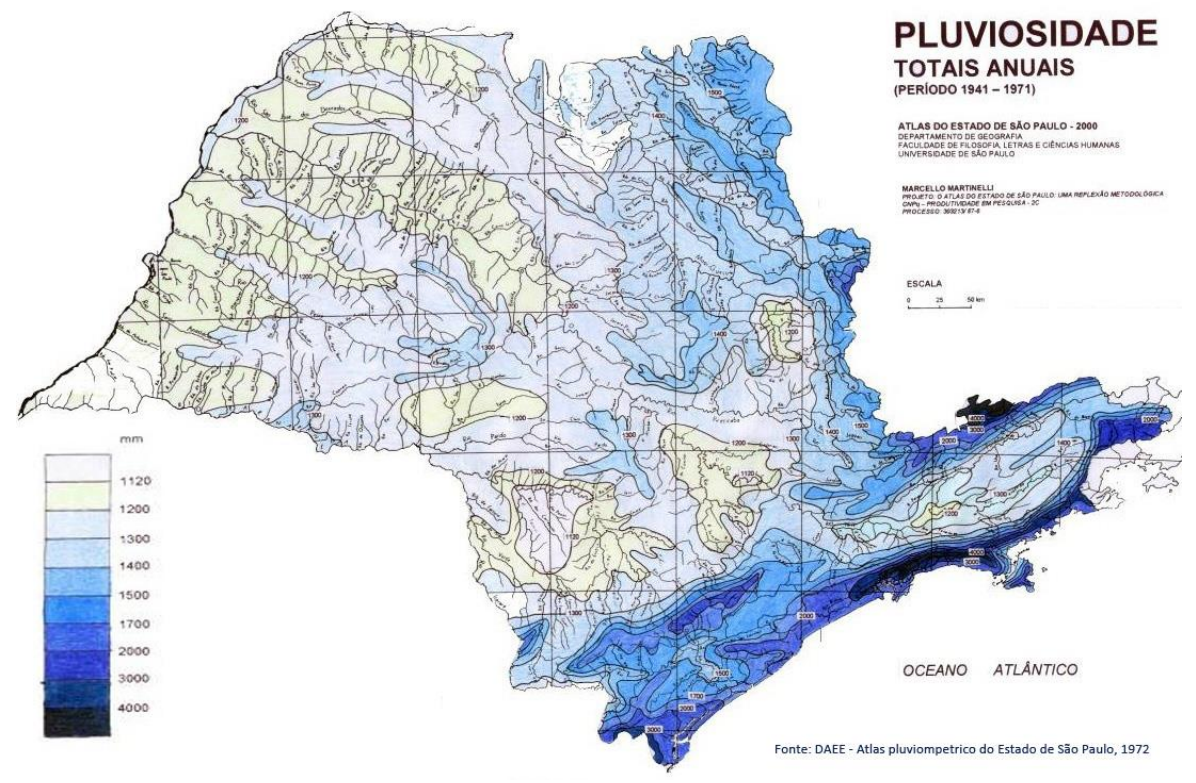

Fonte: DAEE, 1972 apud MARTINELLI 
O homem tem atuado como fator climático, na medida em que as conseqüências de sua forma de vida e capaz de provocar efeitos contínuos e cumulativos.

Baseado nas temperaturas médias diárias lidas as 7, 14 e 21 horas, ordem visual crescente entre as isolinhas de valores $15,17,18,19,20,21,22$ e $23^{\circ} \mathrm{C}$, Martinelli (2007) apresenta o Mapa 06, com gradiente acompanhando a disposição geral do relevo, que indica valores mais elevados do interior para o litoral. (MARTINELLI, 2008, p. 07)

Mapa 06: Temperaturas Médias Anuais para o Estado de São Paulo

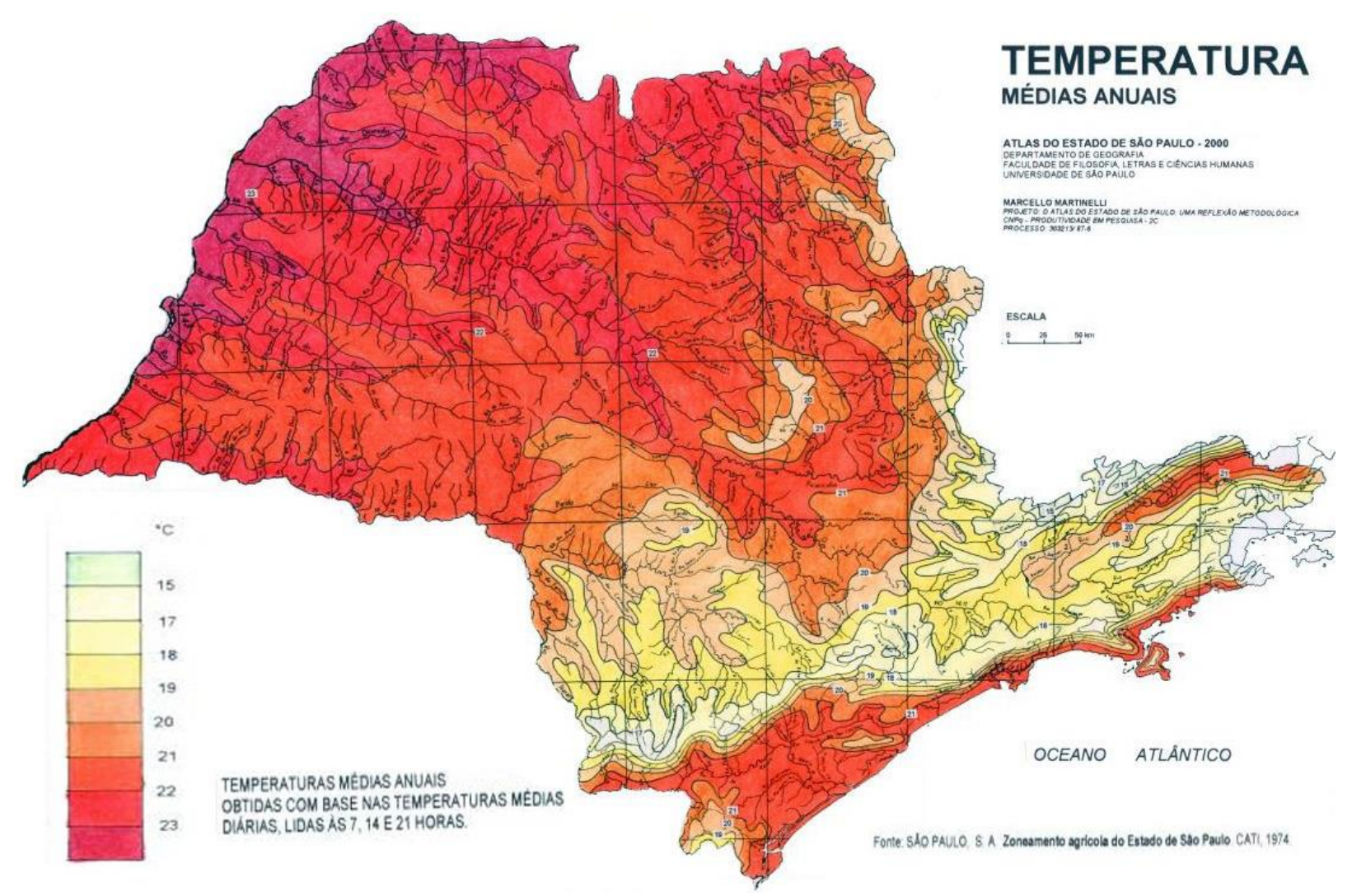

Fonte: CATI, 1974 apud MARTINELLI

Aumentar a probabilidade de incêndios em pastagens, ressecamento da pele, sangramento do nariz, são exemplos dos prejuízos que podem ser causados pela falta de umidade relativa, apresentada por Martinelli (2007, p. 08) no Mapa 07, 
Mapa 07: Umidade Relativa Anual

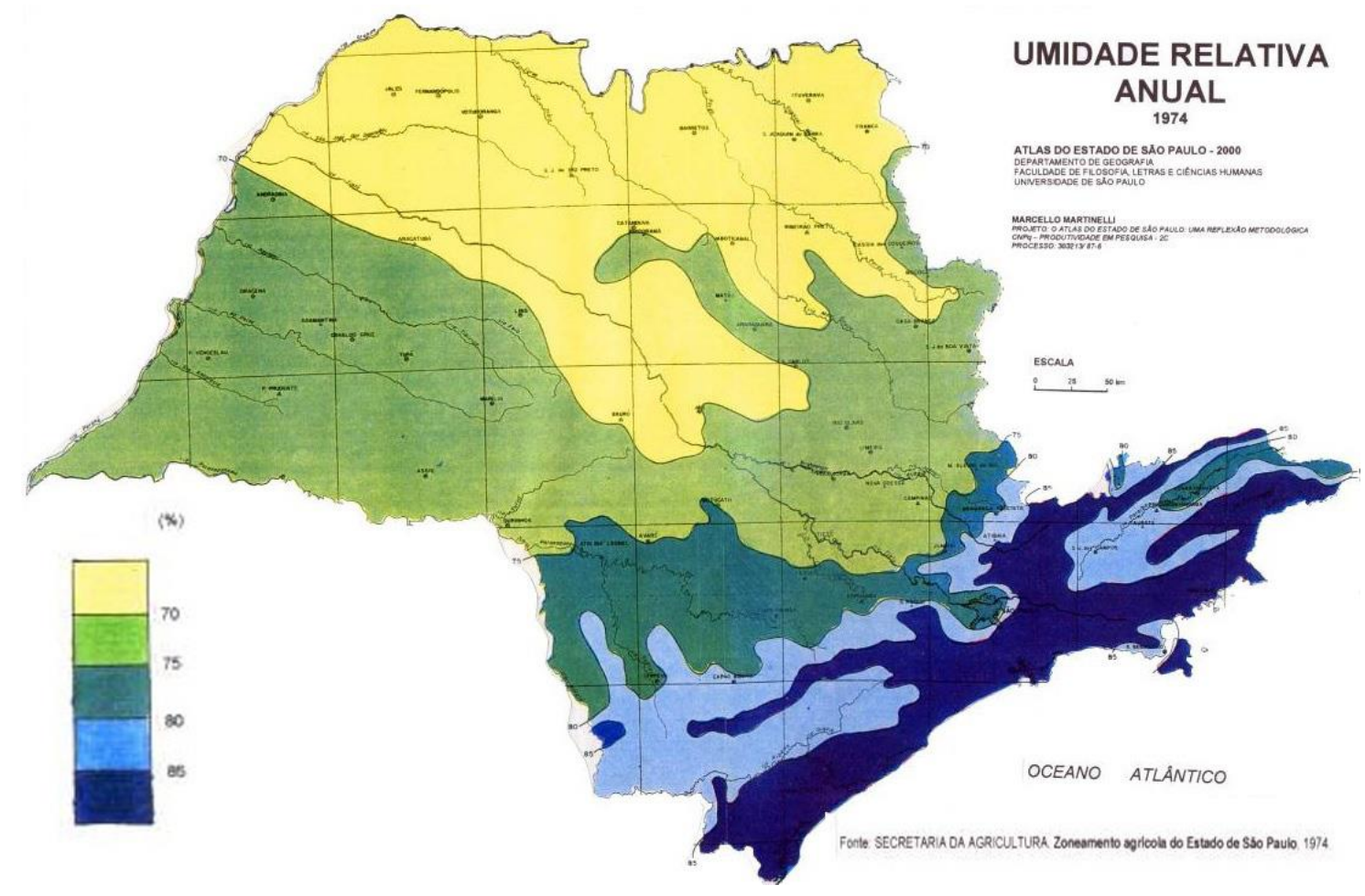

Fonte: Sec. de Agricultura, 1974 apud MARTINELLI

Razão entre a pressão de vapor de água na atmosfera e a pressão de vapor saturado na mesma temperatura, a umidade relativa do ar, ou falta dela, é capaz de provocar grandes manifestações de desconforto nos indivíduos. Utilizada pela metereologia no processo de previsão do tempo, essa umidade é decorrente de uma das fases do ciclo hidrológico, entendida como o processo de evaporação da água.

Para Lacativa (1983), a geada é um fenômeno microclimático que consiste na formação de finos cristais de gelo que se depositam sobre as superfícies, quando as temperaturas ficam abaixo do ponto de congelamento, fazendo com que o vapor d'água da umidade atmosférica passe diretamente ao estado sólido, por sublimação. 
Mapa 08: Ocorrência de Geada no Estado de São Paulo

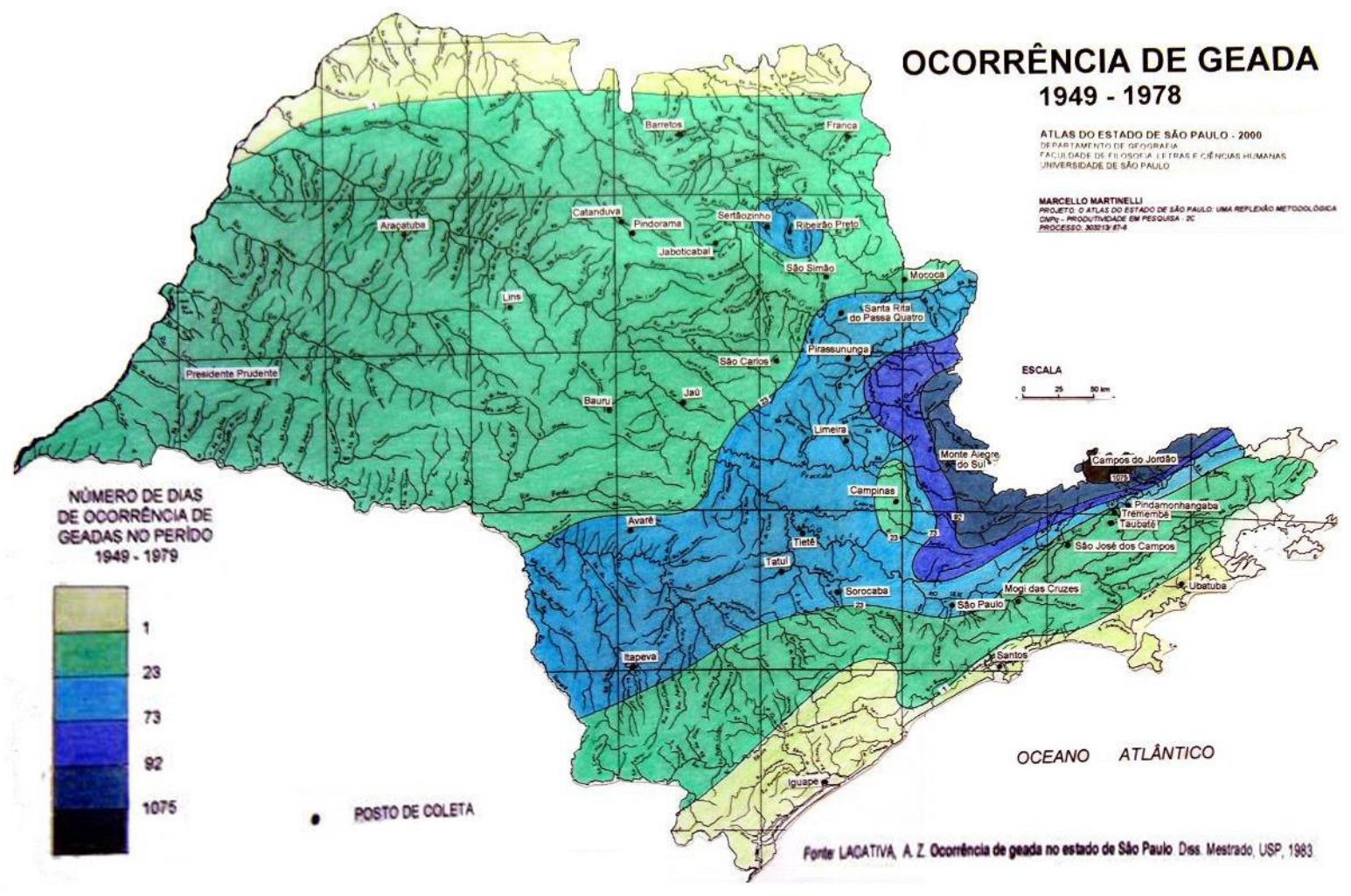

Fonte: LACATIVA, 1983 apud MARTINELLI

A ocorrência de geada no estado de São Paulo está vinculada à participação mais freqüente e intensa das incursões das massas polares, no período de maio até final de agosto. Pode apresentar picos em julho, em episódios em que o centro de alta pressão estaciona ou passa sobre o lugar, deixando o céu claro e com intensa irradiação noturna, sendo favorecida pelo céu claro, ausência de ventos, baixa umidade relativa do ar, temperaturas baixas.

O fenômeno se concentra nas unidades morfoesculturais do Planalto Atlântico, Depressão Periférica e Planalto Ocidental do relevo paulista. Na primeira, acontece por conta da presença marcante do fator altitude; nas duas últimas, ocorre em virtude de tais conjuntos espaciais estarem à mercê da trajetória dos fluxos da massa de ar polar continental. De acordo com o relevo, os fundos de vale são os mais vulneráveis, tendo em vista a acumulação de ar frio em suas baixadas, favorecendo as inversões térmicas.

Segundo o CEPAGRI da UNICAMP (2012), a ocorrência de geadas na região 
sudeste concentra-se nos meses de junho a agosto, com casos excepcionais em maio e setembro. De modo geral, ocorrem geadas fracas a cada $4 / 5$ anos, fortes a cada 9/11 anos e severas a cada 18/20 anos.

O Mapa 09 elaborado por Setzer (1966) baseia-se no índice da efetividade da precipitação anual.

Mapa 09: Classificação Climática pela efetividade da Precipitação em de São Paulo

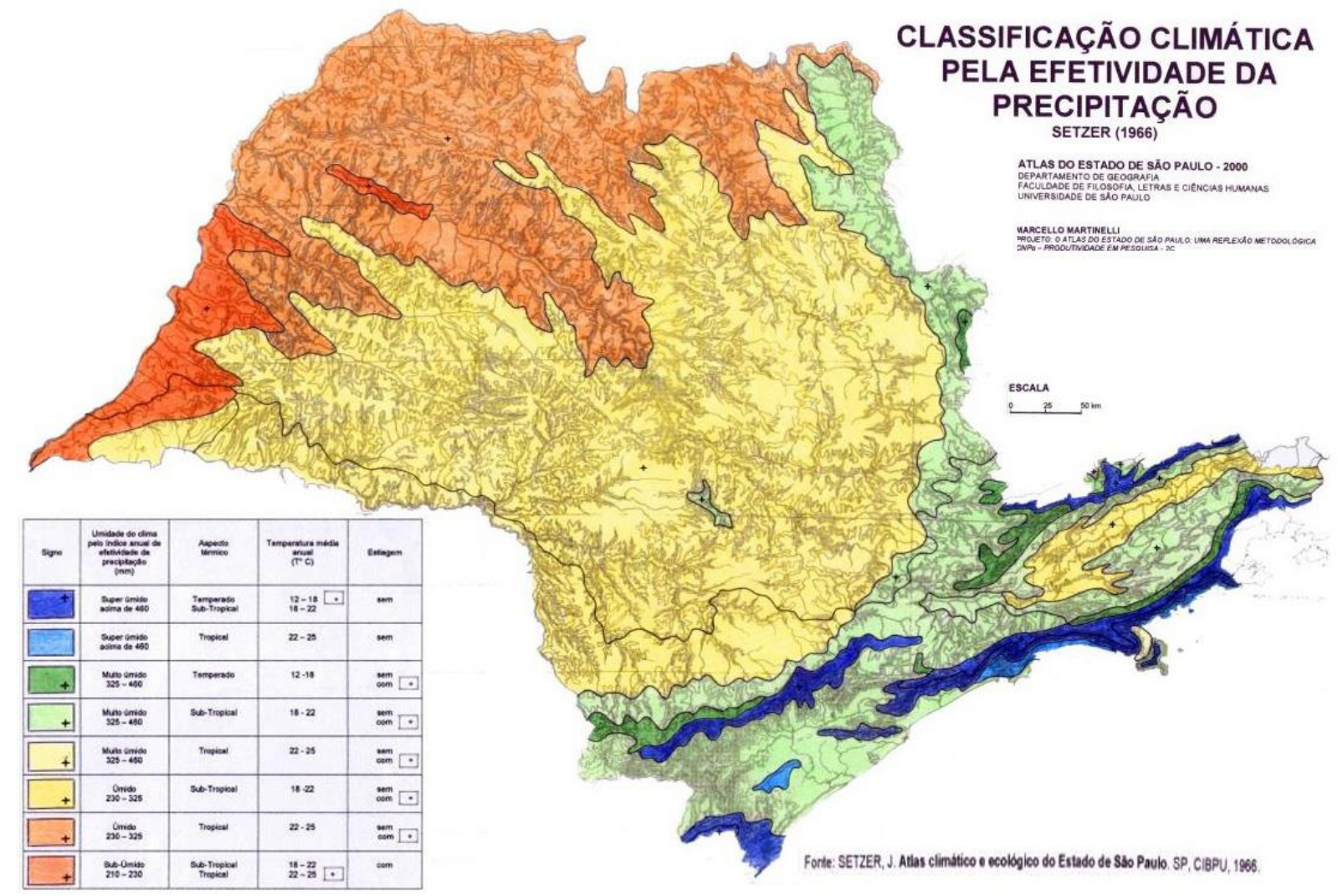

Fonte: SETZER apud MARTINELLI

A efetividade da precipitação anual é um índice de umidade obtido por cálculo que leva em conta as chuvas e as temperaturas na mesma fórmula. É calculado dividindo o total médio de chuvas do mês por 2 elevado à potencia 1/10 da respectiva temperatura média. A soma dos 12 índices mensais é o índice anual. Identificam-se no estado, os climas: Super-úmido temperado, Muito úmido subtropical, Muito úmido tropical, Úmido tropical, Úmido subtropical, Sub-úmido tropical e Sub-úmido subtropical. 
Desenvolvido pelo autor com dados do CEPAGRI da UNICAMP, o quadro 02 apresenta informações sobre a localização das Estâncias Climáticas para o Estado de São Paulo, a altitude e o enquadramento climático pelo Sistema Köppen.

Quadro 02: Dados geográficos das Estâncias Climáticas em São Paulo

\begin{tabular}{l|c|c|c|c|c|c|c|c|c|c|r|r|} 
& & Analândia & $\begin{array}{c}\text { Bragança } \\
\text { Paulista }\end{array}$ & Caconde & $\begin{array}{c}\text { Campos } \\
\text { Novos } \\
\text { Paulista }\end{array}$ & Cunha & Morungaba & Nuporanga & $\begin{array}{c}\text { Santa R. } \\
\text { do Passa } \\
\text { Quatro }\end{array}$ & $\begin{array}{c}\text { Santo } \\
\text { Antonio } \\
\text { do Pinhal }\end{array}$ & $\begin{array}{c}\text { S. Bento } \\
\text { do } \\
\text { Sapucai }\end{array}$ & \\
\hline Latitude & 22.90 & 22.34 & 21.18 & 22.21 & 23.20 & 22.31 & 20.26 & 21.25 & 22.29 & 22.24 & Alt. Méd & 798,7 \\
\hline Longitude & 47.24 & 46.19 & 46.22 & 50.00 & 44.34 & 46.28 & 47.27 & 47.16 & 45.24 & 45.26 & Alt. Mín & 510 \\
\hline Altitude & 677 & 840 & 820 & 510 & 860 & 760 & 780 & 760 & 1100 & 880 & Alt. Máx & 1100
\end{tabular}

Fonte: CEPAGRI - UNICAMP

Se analisada a altitude Campos Novos Paulista e Santo Antonio do Pinhal encontram-se em discrepância em relação às demais localidades. Se o quesito é classificação climática, Nuporanga também destoa.

O Quadro 03 apresenta o volume de chuvas médio mensal e também neste quesito certas discrepâncias são encontradas.

Quadro 03: Volume de Chuvas para as Estâncias Paulistas

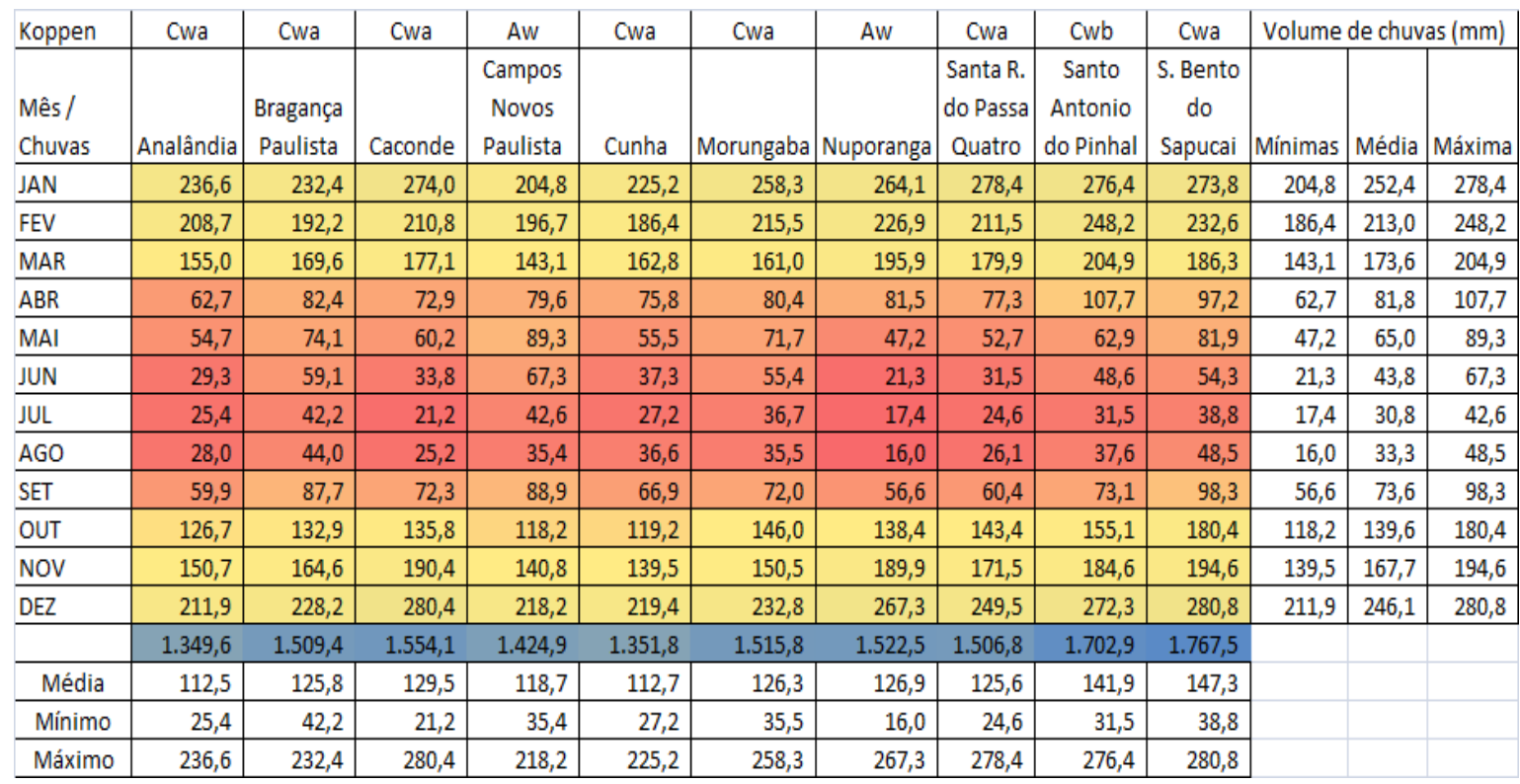

Fonte: Produzido pelo autor com dados do CEPAGRI - UNICAMP (2012) 
Enquanto Analândia e Cunha equiparam-se nos menores volumes de chuva, Santo Antonio do Pinhal e São Bento do Sapucaí, disputam os maiores volumes. Esta condição pluviométrica é apontada também no trabalho proposto por Martinelli (2007), e foi apresentada no quadro PLUVIOSIDADE - TOTAIS ANUAIS.

Em relação ao clima Cunha, Analândia e São Bento do Sapucaí estão classificadas como Cwa, Santo Antonio do Pinhal aparece como Cwb, donde se deduz que a condição pluviométrica, não esta diretamente relacionada ao tipo de Clima, admitindo a influência de outros fatores em sua composição. As médias para as temperaturas máximas, estão representadas no Quadro 04 que apresenta Santo Antonio do Pinhal com 100 \% das menores máximas enquanto Campos Novos Paulista e Nuporanga dividem a supremacia.

Quadro 04: Temperaturas Máximas para as Estâncias Paulistas

\begin{tabular}{|c|c|c|c|c|c|c|c|c|c|c|c|c|c|}
\hline Koppen & Cwa & Cwa & Cwa & Aw & Cwa & Cwa & Aw & Cwa & cwb & Cwa & \multicolumn{3}{|c|}{ Das máximas } \\
\hline $\begin{array}{l}\text { Mês/ } \\
\text { Máximas }\end{array}$ & Analândia & $\begin{array}{l}\text { Bragança } \\
\text { Paulista }\end{array}$ & Caconce & $\begin{array}{l}\text { Campos } \\
\text { Novos } \\
\text { Paulista } \\
\end{array}$ & Cunha & Morungaba & Nuporanga & $\begin{array}{c}\text { Santa R. } \\
\text { do Passa } \\
\text { Quatro }\end{array}$ & $\begin{array}{c}\text { Santo } \\
\text { Antonio } \\
\text { do Pinhal }\end{array}$ & $\begin{array}{c}\begin{array}{c}\text { S. Bento } \\
\text { do } \\
\text { Sapucai }\end{array} \\
\end{array}$ & Mínimas & Média & Máxima \\
\hline JAN & 29,4 & 28,0 & 28,4 & 30,6 & 27,9 & 28,7 & 28,9 & 28,9 & 26,1 & 27,8 & 26,1 & 28,5 & 30,6 \\
\hline FEV & 29,5 & 28,0 & 28,4 & 30,7 & 27,8 & 28,7 & 28,9 & 28,9 & 26,0 & 27,8 & 26,0 & 28,5 & 30,7 \\
\hline MAR & 29,2 & 27,7 & 28,3 & 30,3 & 27,5 & 28,3 & 28,8 & 28,7 & 25,7 & 27,4 & 25,7 & 28,2 & 30,3 \\
\hline ABR & 27,7 & 25,9 & 27,0 & 28,6 & 25,7 & 26,6 & 27,9 & 27,3 & 24,0 & 25,8 & 24,0 & 26,7 & 28,6 \\
\hline $\mathrm{MAI}$ & 25,8 & 24,0 & 25,3 & 26,6 & 23,8 & 24,6 & 26,3 & 25,6 & 22,3 & 23,9 & 22,3 & 24,8 & 26,6 \\
\hline JUN & 24,8 & 22,9 & 24,3 & 25,5 & 22,6 & 23,5 & 25,4 & 24,6 & 21,2 & 22,9 & 21,2 & 23,8 & 25,5 \\
\hline JUL & 25,0 & 23,0 & 24,6 & 25,7 & 22,8 & 23,7 & 25,7 & 24,8 & 21,4 & 23,0 & 21,4 & 24,0 & 25,7 \\
\hline AGO & 27,2 & 25,0 & 26,9 & 27,9 & 24,7 & 25,7 & 28,2 & 27,1 & 23,1 & 25,0 & 23,1 & 26,1 & 28,2 \\
\hline SET & 28,3 & 26,1 & 28,2 & 28,8 & 25,8 & 26,7 & 29,6 & 28,4 & 24,5 & 26,2 & 24,5 & 27,3 & 29,6 \\
\hline OUT & 28,7 & 26,6 & 28,3 & 29,4 & 26,3 & 27,2 & 29,4 & 28,5 & 24,8 & 26,6 & 24,8 & 27,6 & 29,4 \\
\hline NOV & 28,9 & 27,1 & 28,2 & 29,9 & 26,9 & 27,8 & 29,1 & 28,6 & 25,2 & 27,0 & 25,2 & 27,9 & 29,9 \\
\hline DEZ & 28,8 & 27,2 & 28,0 & 29,9 & 27,0 & 27,8 & 28,6 & 28,3 & 25,2 & 27,0 & 25,2 & 27,8 & 29,9 \\
\hline Média & 27,8 & 26,0 & 27,2 & 28,7 & 25,7 & 26,6 & 28,1 & 27,5 & 24,1 & 25,9 & & & \\
\hline Mínimo & 24,8 & 22,9 & 24,3 & 25,5 & 22,6 & 23,5 & 25,4 & 24,6 & 21,2 & 22,9 & & & \\
\hline Máximo & 29,5 & 28,0 & 28,4 & 30,7 & 27,9 & 28,7 & 29,6 & 28,9 & 26,1 & 27,8 & & & \\
\hline
\end{tabular}

Fonte: Produzidos pelo autor com dados do CEPAGRI - UNICAMP 
Quadro 05: Temperaturas Médias para as Estâncias Paulistas

\begin{tabular}{|c|c|c|c|c|c|c|c|c|c|c|c|c|c|}
\hline Koppen & Cwa & Cwa & Cwa & $\mathrm{Aw}$ & Cwa & Cwa & $A W$ & Cwa & Cwb & Cwa & \multicolumn{3}{|c|}{ Das médias } \\
\hline $\begin{array}{l}\text { Mês / } \\
\text { Mécias }\end{array}$ & Analândia & $\begin{array}{c}\text { Bragança } \\
\text { Paulista }\end{array}$ & Caconde & $\begin{array}{c}\text { Campos } \\
\text { Novos } \\
\text { Paulista } \\
\end{array}$ & Cunha & Morungaba & Nuporanga & $\begin{array}{c}\text { Santa R. } \\
\text { do Passa } \\
\text { Quatro }\end{array}$ & $\begin{array}{c}\text { Santo } \\
\text { Antonio } \\
\text { do Pinhal }\end{array}$ & $\begin{array}{c}\text { S. Bento } \\
\text { do } \\
\text { Sapucai }\end{array}$ & Mínimas & Média & Máxima \\
\hline JAN & 23,0 & 22,6 & 23,0 & 24,8 & 22,4 & 23,1 & 23,4 & 23,4 & 20,9 & 22,4 & 20,9 & 22,9 & 24,8 \\
\hline FEV & 24,0 & 22,7 & 23,1 & 25,0 & 22,5 & 23,3 & 23,5 & 23,5 & 20,9 & 22,5 & 20,9 & 23,1 & 25,0 \\
\hline MAR & 23,5 & 22,1 & 22,6 & 24,5 & 21,9 & 22,7 & 23,2 & 23,0 & 20,4 & 21,9 & 20,4 & 22,6 & 24,5 \\
\hline ABR & 21,4 & 19,9 & 20,8 & 22,3 & 19,7 & 20,5 & 21,4 & 21,1 & 18,3 & 19,8 & 18,3 & 20,5 & 22,3 \\
\hline MAI & 19,1 & 17,6 & 18,6 & 19,9 & 17,4 & 18,2 & 19,3 & 18,9 & 16,0 & 17,5 & 16,0 & 18,3 & 19,9 \\
\hline JUN & 17,9 & 16,3 & 17,4 & 19,6 & 16,1 & 16,8 & 18,3 & 17,7 & 14,7 & 16,2 & 14,7 & 17,1 & 19,6 \\
\hline JUL & 17,8 & 16,1 & 17,3 & 18,5 & 15,9 & 16,7 & 18,2 & 17,5 & 14,5 & 16,0 & 14,5 & 16,9 & 18,5 \\
\hline AGO & 19,6 & 17,7 & 19,1 & 20,3 & 17,4 & 18,3 & 20,2 & 19,4 & 16,0 & 17,6 & 16,0 & 18,6 & 20,3 \\
\hline SET & 21,1 & 19,2 & 20,8 & 21,7 & 19,0 & 19,8 & 22,0 & 21,0 & 17,7 & 19,2 & 17,7 & 20,2 & 22,0 \\
\hline OUT & 22,2 & 20,4 & 21,8 & 22,8 & 20,1 & 20,9 & 22,8 & 22,0 & 18,8 & 20,3 & 18,8 & 21,2 & 22,8 \\
\hline NOV & 22,7 & 21,1 & 22,1 & 23,6 & 20,9 & 21,7 & 22,8 & 22,4 & 19,4 & 21,0 & 19,4 & 21,8 & 23,6 \\
\hline DEZ & 23,2 & 21,8 & 22,5 & 24,2 & 21,6 & 22,4 & 23,1 & 22,8 & 20,1 & 21,6 & 20,1 & 22,3 & 24,2 \\
\hline Média & 21,3 & 19,8 & 20,8 & 22,3 & 19,6 & 20,4 & 21,5 & 21,1 & 18,1 & 19,7 & & & \\
\hline Mínimo & 17,8 & 16,1 & 17,3 & 18,5 & 15,9 & 16,7 & 18,2 & 17,5 & 14,5 & 16,0 & & & \\
\hline Máximo & 24,0 & 22,7 & 23,1 & 25,0 & 22,5 & 23,3 & 23,5 & 23,5 & 20,9 & 22,5 & & & \\
\hline
\end{tabular}

Fonte: Produzidos pelo autor com dados do CEPAGRI - UNICAMP

O quadro 06 representa as máximas temperaturas (das mínimas) e neste caso, Santo Antonio do Pinhal apresenta as menores temperaturas enquanto Campos Novos Paulista apresenta as máximas. Chama a atenção a grande diferença encontrada entre os menores e os maiores valores para cada categoria $\left(3,4^{\circ} \mathrm{C}\right.$ a $\left.3,8^{\circ} \mathrm{C}\right)$, para municípios que recebem o mesmo enquadramento. 
Quadro 06: Temperaturas Mínimas para as Estâncias Climáticas Paulistas

\begin{tabular}{|c|c|c|c|c|c|c|c|c|c|c|c|c|c|}
\hline Koppen & Cwa & Cwa & Cwa & Aw & Cwa & Cwa & Aw & Cwa & Cwb & Cwa & \multicolumn{3}{|c|}{ Das mínimas } \\
\hline $\begin{array}{l}\text { Mês / } \\
\text { Mínimas }\end{array}$ & Analância & $\begin{array}{l}\text { Bragança } \\
\text { Paulista }\end{array}$ & Caconde & $\begin{array}{c}\text { Campos } \\
\text { Novos } \\
\text { Paulista }\end{array}$ & Cunha & Morungaba & Nuporanga & $\begin{array}{c}\text { Santa R. } \\
\text { do Passa } \\
\text { Quatro }\end{array}$ & $\begin{array}{c}\text { Santo } \\
\text { Antonio } \\
\text { do Pinhal }\end{array}$ & $\begin{array}{l}\text { S. Bento } \\
\text { do } \\
\text { Sapucai }\end{array}$ & Mínimas & Média & Máxima \\
\hline JAN & 18,2 & 17,1 & 17,5 & 19,1 & 17,0 & 17,6 & 17,9 & 17,9 & 15,6 & 17,0 & 15,6 & 17,5 & 19,1 \\
\hline FEV & 18,5 & 17,4 & 17,7 & 19,3 & 17,2 & 17,8 & 18,1 & 18,1 & 15,9 & 17,2 & 15,9 & 17,7 & 19,3 \\
\hline MAR & 17,7 & 16,5 & 17,0 & 18,6 & 16,4 & 17,0 & 17,5 & 17,3 & 15,0 & 16,4 & 15,0 & 16,9 & 18,6 \\
\hline MAI & 12,5 & 11,2 & 11,9 & 13,2 & 11,0 & 11,7 & 12,4 & 12,1 & 9,7 & 11,1 & 9,7 & 11,7 & 13,2 \\
\hline JUN & 11,0 & 9,7 & 10,5 & 11,8 & 9,5 & 10,2 & 11,2 & 10,8 & 8,2 & 9,6 & 8,2 & 10,3 & 11,8 \\
\hline JUL & 10,5 & 9,1 & 10,0 & 11,2 & 9,0 & 9,6 & 10,7 & 10,3 & 7,7 & 9,1 & 7,7 & 9,7 & 11,2 \\
\hline AGO & 11,9 & 10,4 & 11,4 & 12,6 & 10,2 & 10,9 & 12,2 & 11,7 & 8,9 & 10,3 & 8,9 & 11,1 & 12,6 \\
\hline SET & 13,9 & 12,3 & 13,5 & 14,6 & 12,1 & 12,9 & 14,3 & 13,7 & 10,8 & 12,3 & 10,8 & 13,0 & 14,6 \\
\hline Média & 14,9 & 13,6 & 14,4 & 15,7 & 13,4 & 14,1 & 15,0 & 14,6 & 12,1 & 13,5 & & & \\
\hline Mínimo & 10,5 & 9,1 & 10,0 & 11,2 & 9,0 & 9,6 & 10,7 & 10,3 & 7,7 & 9,1 & & & \\
\hline Máximo & 18,5 & 17,4 & 17,7 & 19,3 & 17,2 & 17,8 & 18,1 & 18,1 & 15,9 & 17,2 & & & \\
\hline
\end{tabular}

Fonte: Produzido pelo autor com dados do CEPAGRI - UNICAMP

\section{CONCLUSÕES}

A implantação das primeiras estâncias em São Paulo, tinham caráter sanitário, daí a origem da primeira nomenclatura, priorizando a cura e tratamento de enfermidades pulmonares. O Estado de São Paulo possui condições climáticas distintas em relação ao restante da Federação, sendo caracterizada por uma zona de transição, com presença de seis tipos climáticos diferenciados. Classificar o clima pode depender do tipo de informação, seu volume e de quem precisa dela, gerando desta forma várias possibilidades de interpretação.

Os critérios legais observados para elevação de um município a condição de estância, são definidos pelo artigo 4ํㅜ da Lei 10.426 de 08 de dezembro de 1971:

I - Temperatura média das mínimas no verão, até $20^{\circ} \mathrm{C}$.

II - Temperatura média das máximas no verão, até $25^{\circ} \mathrm{C}$.

III - Temperatura média das mínimas no inverno, até $18^{\circ} \mathrm{C}$.

IV - Umidade relativa média anual até $60 \%$, admitida a variação, para 
menos, de $10 \%$ do resultado obtido no local.

V - Número anual de horas de insolação superior a duas mil. (ALESP, 2012)

Atualmente são apenas dez os municípios que detém o título, ainda que o Estado disponha de estações e postos metereológicos em quantidade e qualidade suficientes para análises mais precisas e atualizadas.

A umidade relativa do ar varia de mínimos 60\% em média para até $90 \%$, com as regiões próximas do litoral mais úmidas decrescendo na medida em que nos afastamos dela. Os efeitos de massas polares podem ser mais sentidos na região central do Estado

Um olhar mais apurado indica que ainda outros municípios poderão estar enquadrados na medida em que diferenças médias de até $5,1^{\circ} \mathrm{C}$, como entre Nuporanga e Santo Antonio do Pinhal, indicam critérios bastante flexíveis. Aspectos como umidade relativa do ar fundamental a sensação de bem estar do homem, altera-se radicalmente na direção litoral-interior.

Foi percebida uma diferença média de altitude de $590 \mathrm{~m}$ entre Campos Novos Paulista e Santo Antonio do Pinhal, ratificando diferença de climas entre os dois municípios segundo a classificação climática de Köppen. Segundo esta classificação são sete os municípios classificados como Cwa, dois como Aw e um Cwf.

O menor volume de chuvas médio encontrado $(1.349,6 \mathrm{~mm})$ Analândia, contrasta com o maior (1.767,5 mm) de São Bento do Sapucaí em 417,9 mm.

Pelo tudo exposto verifica-se a necessidade de uma revisão dos critérios, com a elaboração de novo paradigma de caráter técnico, para que discrepâncias sejam avaliadas e corrigidas.

\section{REFERÊNCIAS}

AMARAL, Antonio Barreto. Dicionário de História de São Paulo. São Paulo: Imprensa Oficial, 2006. Página 21. 
BRASIL Ministério do Agricultura Disponível em: http://www.agricultura.gov.br/portal/page/portal/Internet-MAPA/paginainicial/vegetal/registros-autorizacoes/protecao-cultivares/publicacoes. Acesso em $21 / 12 / 2012$

HOLANDA, A. B. Novo dicionário Aurélio para a Língua Portuguesa. Versão Eletrônica. 2013

IBGE. Perfil dos municípios brasileiros: Informações municipais. Disponível em: HTTP://www.ibge.gov.br/home/estatistica/economia/perfilmunic/2009/default.shtm. Acesso em: 15/10/2012

INMET - Instituto Nacional de Metereologia (Brasil). Disponível em :

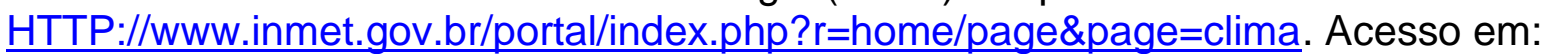
25/04/2013

IPCC - Intergovernmental Panel on Climate Change - Glossary of terms. In: Managing the risks of extreme events and disasters to advance climate change adaptation [Field, C. B., Barros, T. F. Stocker, D. Qin, D. J. Dokken, K. L. Ebi, M. D. Mastrandrea, K. J. Mach, G. K. Plattner, S. K. Allen, M. Tignor, and P. M. Midgley(Eds)]. A special reporto f working groups I and II of the Intergovernmental Panel on Climate Change (IPCC). Cambridge University Press, Cambridge, UK, and New York, NY, USA, PP. 555-564

MARTINELLI, M. Clima do Estado de São Paulo, Confins [Online], 8 / 2010, posto online em 14 março 2010, Consultado em 31 agosto 2012. URL. Disponível em: HTTP://confins.revues.org/6348. Acesso em 10/01/2013

ROLIM, G. De S.; CAMARGO, M. B. P. De; LANIA, D. G.; MORAES, J. F. L. de. Classificação climática de köppen e de Thornthwaite e sua aplicabilidade na determinação de zonas agroclimáticas para o Estado de São Paulo. Bragantia, Campinas, v. 66, n. 4, p. 711-720, 2007

SÃO PAULO (Estado) - SECRETARIA DE TURISMO - Departamento de Apoio e Desenvolvimento das Estâncias - DADE. Estâncias. São Paulo. 2012. Disponível em: HTTP://www.turismo.sp.gov.br/dade/estancias.html. Acesso em 18/08/2012.

SÃO PAULO (Estado). Secretaria de Turismo - Departamento de Apoio ao Desenvolvimetno das Estâncias - DADE, Manual de Convênios. São Paulo. 2012. Disponível em: HTTP://www.turismo.sp.gov.br/dade/manual-de-convenios-comdade.html. Acesso em 22/02/2012

SÃO PAULO (Estado). Lei 10.426 de 08 de dezembro de 1971. Estabelece requisitos mínimos para a criação de estâncias. Disponível em: http://www.al.sp.gov.br/repositorio/legislacao/lei/1971/lei\%20n.10.426,\%20de\%2008. $\underline{12.1971 . \mathrm{htm}}$

SÃO PAULO (Estado). Lei 2.140 de 01 de outubro de 1926. Cria uma Prefeitura 
Sanitária em Campos do Jordão e autoriza a acquisição de todos os bens pertencentes à Companhia Guarujá. Disponível em:

http://www.al.sp.gov.br/repositorio/legislacao/lei/1926/lei\%20n.2.140,\%20de\%2001.1 0.1926.htm

SEADE - Fundação Sistema Estadual de Análise de Dados - Histórico Municipal de Campos do Jordão. Disponível em:

http://www.seade.gov.br/produtos/perfil/hist/hist 97.pdf Acesso em: 24/05/2013.

SETZER, J. Atlas climático e ecológico do estado de São Paulo. São Paulo: CIBPU, 1966.

PINTO H.S.; ZULLO Jr J. Geadas: Condições de ocorrência e cuidados. Disponível em: http://www.cpa.unicamp.br/artigos-especiais/geadas.html Acesso em 18/09/2012

CEPAGRI - Centro de Pesquisas Metereológicas e Climáticas Aplicadas a Agricultura. Dados Climáticos da estâncias climáticas. Disponíveis em:

http://www.cpa.unicamp.br/outras-informacoes/clima muni 099.html. Caconde http://www.cpa.unicamp.br/outras-informacoes/clima muni 112.html - Campos Novos Paulista

http://www.cpa.unicamp.br/outras-informacoes/clima muni 152.html - Cunha http://www.cpa.unicamp.br/outras-informacoes/clima muni 087.html - Bragança Paulista

http://www.cpa.unicamp.br/outras-informacoes/clima muni 023.html - Analândia http://www.cpa.unicamp.br/outras-informacoes/clima muni 360.html - Morungaba http://www.cpa.unicamp.br/outras-informacoes/clima muni 382.html - Nuporanga http://www.cpa.unicamp.br/outras-informacoes/clima muni 531.html - Sta Rita do Passa Quatro

http://www.cpa.unicamp.br/outras-informacoes/clima muni 542.html - Santo Antonio do Pinhal

http://www.cpa.unicamp.br/outras-informacoes/clima muni 546.html - São Bento do Sapucai 